\title{
"IRMÃOS CONCEBIDOS ILEGALMENTE SERÃO ENVIADOS PARA HIBERNAÇÃO”: PRÁTICAS PEDAGÓGICAS EM IMBRICAÇÕES ENTRE OBRAS AUDIOVISUAIS, BIOPODER, BIOPOLÍTICA E DIREITO
}

\author{
Ana Clara Correa Henning ${ }^{1}$ \\ Amanda D'Andréa Löwenhaupt
}

\section{Resumo}

Propõe-se protocolo de utilização pedagógica de mídias e cultura popular para desenvolver conhecimentos sobre direito e suas imbricações com os conceitos de biopoder e biopolítica. As práticas apresentadas têm por público alvo crianças, adolescentes e adultos, sendo escolhidas três obras, cada uma delas correspondente a uma das diferentes faixas etárias. Para a elaboração do presente texto, utilizou-se de fundamentação teórica jurídica e dos estudos foucaultianos, assim como estudo empírico das obras audiovisuais.

Palavras-chave: Estudos foucaultianos; Biopoder; Biopolítica; Obras audiovisuais; Práticas pedagógicas.

\section{"ILLEGALLY CONCEIVED SIBLINGS WILL BE REMANDED TO CRYOSLEEP": PEDAGOGICAL PRACTICES IN IMBRICATION BETWEEN AUDIOVISUAL WORKS, BIOPOWER, BIOPOLITICS AND LAW}

\begin{abstract}
It is proposed a protocol of pedagogical use of media and popular culture to develop knowledge about law and its imbrications with the concepts of biopower and biopolitics. The presented practices have as a target children, teenagers and adults, with three chosen works, each for one of the different age groups. In the making of this text, the theoretical foundation used was juridic and that of foucaultian studies, as well as the empirical study of the audiovisual works.
\end{abstract}

Keywords: Foucaultian studies; Biopower; Biopolitics; Audiovisual works; Pedagogical practices.

\section{Introdução}

Apresenta-se o protocolo de atuação de três propostas de utilização de mídias e cultura popular para desenvolver conhecimentos sobre direito e suas imbricações com os conceitos de biopoder e biopolítica. O público alvo de tais práticas pedagógicas varia de acordo com o tema e o artefato cultural eleito, abrangendo desde crianças e adolescentes até pessoas já na

\footnotetext{
1 Doutora em Direito (UFSC, 2016 - bolsa CAPES). Professora Adjunta na Faculdade de Direito da UFPel, Graduação e Programa de Pós-Graduação em Direito. Coordena do Grupo de Pesquisa, Ensino e Extensão Inventar: arte e construção do conhecimento jurídico (CNPq), bem como projetos voltados ao ensino do direito à comunidade por meio de produtos e processos didático-jurídicos.
} 
fase adulta. O objetivo geral deste texto, assim, é o de mostrar de que maneira se pode contextualizar os conceitos referidos em obras audiovisuais contemporâneas, apontando suas conexões com o campo jurídico.

A importância desta pesquisa e das práticas que lhe seguem reside na aproximação entre a academia e a sociedade, buscando traduzir conceitos para possibilitar a densificação da democratização do conhecimento jurídico. A fim de elaborar-se a investigação que fundamenta o presente protocolo e este texto, utilizou-se de pesquisa bibliográfica, abrangendo obras jurídicas e os estudos foucaultianos, e empírica, por meio da análise de três obras audiovisuais.

As obras utilizadas foram: What Happened to Monday (NETFLIX, 2017), o episódio A Clone of My Own (20TH CENTURY FOX TELEVISION, 2000), da série Futurama e o episódio The Zoo (CARTOON NETWORK STUDIOS, 2017), da série Steven Universe. A partir delas, procurou-se observar como atuam os conceitos de biopoder e biopolítica em relação ao direito de reprodução, ao direito à própria morte e ao direito de autodeterminação.

A escrita que segue, assim, está organizada em três partes. Inicialmente, contextualiza-se o surgimento do biopoder e de suas técnicas, apresenta-se os conceitos relacionados e aponta-se algumas conexões jurídicas possíveis. A seguir, o direito e o ensino jurídico modernos são problematizados, assim como resistências possibilitadas por meio da conexão entre arte, mídias e direito. Ao fim, o protocolo das práticas pedagógicas é apresentado com o objetivo de debater certas tensões emergentes no campo do direito.

\section{A utilização de cultura popular para contextualizar os conceitos foucaultianos de biopoder e biopolítica: o que o direito tem a ver com isso?}

Michel Foucault (2001) aponta que, por volta da segunda metade do século XVIII, modificações profundas ocorreram no Ocidente, abrangendo toda sorte de dimensões: epistêmicas, econômicas, políticas, dentre outras tantas. Emergiram, assim, uma série de fenômenos sociais, como aumento da riqueza, crescimento demográfico, desenvolvimento dos 
portos e o incremento do sistema capitalista. Somaram-se transformações trazidas pelas duas grandes revoluções europeias: Francesa e Industrial.

A partir daí, o poder sobre a vida, tal como presenciado, desenvolveu-se principalmente em duas formas interligadas, ainda que de origem temporal diversa. Ou seja, as relações de poder tomam uma dupla face: disciplinária e biopolítica. O poder disciplinar, segundo o autor, toma consistência a partir do século XVIII, centrando-se no corpo máquina, interessando-lhe o seu adestramento, a ampliação de suas forças e de sua docilidade por meio de procedimentos disciplinares - a "anátomo-política do corpo humano" (FOUCAULT, 2014, p. 150). Tornando-se disciplinares, tais poderes reorganizaram a sociedade de maneira à docilizar os corpos individuais e, no processo, construir um conhecimento minucioso sobre eles (FOUCAULT, 2001).

Por sua vez, o autor caracteriza o biopoder "pela administração dos corpos e pela gestão calculista da vida" (FOUCAULT, 2014, p. 131). Ainda sobre isso, afirma:

\footnotetext{
Pode-se dizer que o velho direito de causar a morte ou deixar viver foi substituído por um poder de causar a vida ou devolver à morte. [...] Agora é sobre a vida e ao longo de todo o seu desenrolar que o poder estabelece seus pontos de fixação; a morte é o limite, o momento que lhe escapa; ela se torna o ponto mais secreto da existência, o mais "privado" (FOUCAULT, 2014, p. 130).
}

Foucault aponta o final do século XVIII como o momento da emergência dessa outra face do poder, uma tecnologia que se dirige à população, procurando controlar processos inerentes à vida (FOUCAULT, 2010), que vai centrar-se no corpo-espécie, em seus processos biológicos: nascimento, saúde, longevidade, mortalidade. O poder se ocupará também de controles reguladores, em uma biopolítica da população; um poder cuja prioridade será o investimento sobre a vida (FOUCAULT, 2014). Aponta-se, aqui, a diferença entre biopoder voltado à população - e a biopolítica - mecanismos de aplicação do biopoder (FOUCAULT, 2010).

Foucault entende que o desenvolvimento do capitalismo teve no bipoder um elemento indispensável, que lhe garantiu o controle dos corpos no aparelho de produção e o ajustamento da população aos processos econômicos. Para o autor: "[...] deveríamos falar de 'biopolítica' para designar o que faz com que a vida e seus mecanismos entrem no domínio 
dos cálculos explícitos, e faz do poder-saber um agente de transformação da vida humana" [grifos no original] (FOUCAULT, 2014, p. 154).

Percebe-se, em decorrência desse pensamento, que o próprio Estado de Bem-Estar Social se apresenta como o ápice do biopoder, na medida em que os aspectos da vida biológica são controlados pelo Estado, que determina, por exemplo, a obrigatoriedade de vacinas para prevenir doenças, a previdência para garantir a vida na velhice, entre outros aspectos (BRAGA; VLACH, 2004).

O biopoder é, ainda, posteriormente definido por Foucault (2008, p. 03) como "o conjunto dos mecanismos pelos quais aquilo que, na espécie humana, constitui suas características biológicas fundamentais vai poder entrar numa política, numa estratégia geral de poder.". Esse tipo de poder não se limita ao controle direto da vida através da saúde, estando presente em regulações que pretendem controlar algum aspecto da vida biológica. Assim, a biopolítica, se traduz em políticas públicas que organizam. por exemplo, controles de aspectos sociais da vida humana.

São exemplos de biopolítica, historicamente empregados, a vedação do suicídio apresentada por Foucault (2014, p. 130) como "usurpar direito de morte exclusivo dos soberanos" - e a vedação da eutanásia; a proibição do aborto; a regulação da esterilização voluntária condicionada ao atendimento de idade mínima ou número mínimo de filhos vivos; os acordos de redução de açúcar e gordura em alimentos industrializados.

Da mesma forma, pode-se referir às regulações trabalhistas, como jornada de trabalho, intervalo, férias, uso de Equipamento de Proteção Individual (EPI) e aposentadoria compulsória. Entretanto, é interessante notar que as mesmas técnicas biopolíticas podem estabelecer a obrigatoriedade de aborto para certos grupos étnicos aliada à vedação de aborto para outros; a esterilização forçada de certos grupos étnicos, de condenados por crimes, ou de pessoas com doenças mentais ou deficiências.

Para traduzir de maneira mais concreta a forma pela qual o biopoder se apresenta, pode-se falar na discussão com relação ao direito à morte. Esse direito, em geral tratado no aspecto do direito à morte digna, é tão somente o direito de optar pela morte ao invés do prolongamento da vida. Ele vem sendo discutido, na maioria das vezes, no contexto de doenças terminais ou doenças crônicas incuráveis que causem grande sofrimento para o 
paciente, e também de tratamentos inúteis ou pouco eficientes que causem sofrimento, desconforto ou diminuição da qualidade de vida. O direito a morte pode ser efetivado através do suicídio, da eutanásia ativa ou da eutanásia passiva (AITH, 2007).

Morrer é um comportamento natural de toda vida biológica, mas o biopoder do Estado se manifesta na medida em que tenta impedir o resultado morte, ainda que contra a vontade do indivíduo e às custas de grave sofrimento. Parte da literatura especializada entende que, ao negar ao sujeito a capacidade de decidir entre uma morte hospitalar prolongada e uma morte domiciliar breve, a vida se torna antes de um direito, um dever, uma obrigação de caráter moral (AÑEZ, 2014).

Tais discussões, entretanto, são ainda pouco exploradas no campo do direito. Talvez isso também se deva pela ausência de debates e aprofundamento de tais temáticas na própria academia jurídica. O ensino do direito, permeado por métodos tradicionais, poderia se beneficiar ao trazer à discussão não somente essas questões, mas igualmente adotando outras maneiras de pensar e construir o conhecimento. É nesse sentido que, pensa-se, a conexão entre arte e mídias culturais pode ser uma estratégias de resistência e inovação.

\section{Ensino do Direito, modernidade e resistências por meio de artefatos artísticos- culturais}

Vem-se discutindo, já há algum tempo, as características modernas tanto do direito quanto de seu ensino. Ambos nasceram marcados pela modernidade, em especial naquilo que se relaciona com os princípios da neutralidade, da igualdade e da imparcialidade jurídicas. Partes processuais formalmente iguais, um sistema jurídico neutro e que assegure direitos a todas e todos os cidadãos somados à imparcialidade estatal tanto na elaboração quanto na aplicação da lei são suas decorrências (KIPPER, 2000; HENNING; FAGUNDES, 2018).

Na prática da academia, tais princípios também exercem influência na linguagem jurídica erudita e hermética, com sua pretensão final de inteligibilidade pelos iniciados; no currículo classificado, com divisões muito demarcadas entre as disciplinas; no distanciamento 
da vida cotidiana e da cultura popular (HENNING, 2008; LEITE, 2014). Constituem-se, assim, relações de poder e de saber assimétricas, com o assujeitamento dos atores pedagógicos (docentes e discentes) de acordo com os papéis que desempenham na produção de tais conhecimentos.

A literatura especializada discute sobre como ocorre a regulação da distribuição de poder no e pelo ensino jurídico. Segundo Kipper (2000), a pedagogia do direito moderno possui basicamente três características: descontextualização, dogmatismo e unidisciplinariedade. Estas estão presentes na medida em que os conteúdos ministrados se apresentam desconectados da vivência dos alunos, que por sua vez os tomam como verdades incontestáveis. O conhecimento abstraído da vida cotidiana não permite uma compreensão mais aprofundada do objeto de estudo, limitado à teorização exposta pelo professor, de modo que a cultura erudita e acadêmica ocupa posição central, sendo com frequência considerada como único discurso legítimo (HENNING, 2008; LEITE, 2014).

Entretanto, novas maneiras de ensinar e de aprender o conhecimento vem sendo exercitadas. Práticas interdisciplinares, currículos mais flexíveis, projetos de pesquisa e de extensão, cada qual a sua maneira, aliam saberes acadêmicos com a cultura popular. Entendese que:

O conhecimento é um instrumento dinâmico que indivíduos e grupos podem usar para abordar questões nas suas vidas. Nesta conformidade, o conhecimento é um tipo de poder pois ajuda a dar às pessoas um certo controlo sobre as suas próprias vidas. Quando o conhecimento é visto como uma simples colecção de fragmentos e retalhos de informação e destrezas organizados por disciplinas separadas, a sua utilização e o seu poder estão confinados pelas suas próprias fronteiras e, por isso mesmo, diminuídos. Por exemplo, a definição de problemas e os meios de os abordar estão limitados ao que é conhecido e considerado problemático no seio de determinada disciplina. Quando se perspectiva o conhecimento de uma forma integrada, torna-se possível definir os problemas de um modo tão amplo tal como existem na vida real, utilizando um corpo abrangente de conhecimento para os abordar (BEANE, 2003, p. 07).

Percebe-se a potência, de pesquisas e práticas que versem sobre a imbricação entre conhecimentos acadêmico-jurídicos e saberes outros, especialmente com aqueles oriundos da 
cultura popular, e com práticas inseridas nas tramas de poder e de saber que constroem a sociedade contemporânea. Da mesma forma, observa-se que tais práticas pedagógicas legitimam iniciativas e organizações discentes e comunitárias, possibilitando a construção de repertórios de ação coletiva e, talvez, resistências ao direito moderno e ao ensino jurídico tradicional (HENNING; FAGUNDES, 2018).

Dentre tais iniciativas, ressalta-se aquelas produzidas a partir de imbricações entre direito e arte. Aponta-se que os estudos sobre essa temática vêm tomando força no início deste século, já havendo diversas obras teóricas que se propõem a tal relação (FRANCA FILHO; LEITE; PAMPLONA FILHO, 2016; LEITE; VAN-DÚNEM; HENNING, 2016; GONZÁLEZ, 2016; LEITE, 2014).

O campo vem se mostrado como foco de resistência ao extremado dogmatismo jurídico, possuíndo inúmeras conexões estudadas, tal como o caso pioneiro do Direito e Literatura (OLIVO, 2012; STRECK; TRINDADE, 2012; DUONG, 2005). Da mesma forma, conexões entre Direito e Cinema (HENNING, 2016; SOUSA; NASCIMENTO, 2011; AZIMOV, 2009), Direito e Artes Visuais (WOLKMER; HENNING, 2017; GONZÁLEZ, 2016; CRAWLEY, 2015; DIAS, 2015), Direito e Teatro (DHALIWAL, 2017; OLIVEIRA; SOUSA, 2013), Direito e Música (FAGUNDES; HENNING, 2017; GRÜNE, 2012; VALERIO, 2007), Direito e Séries Televisivas (VILLEZ, 2014; ROBSON, 2014).

Das mais variadas correntes teóricas, de diversos países, com propostas metodológicas diferenciadas, essas produções possuem em comum a procura pela interdisciplinaridade na compreensão de fatos sociais, reconhecendo em práticas artísticas, muitas das quais localmente construídas, fontes valiosas de saberes jurídicos.

Ressaltamos aqui a imbricação entre direito e cinema e entre direito e séries televisivas. A primeira vem se fortalecendo no Brasil (MARTINEZ, 2015), inclusive no próprio CONPEDI (AQUINO, 2016). A segunda, ainda incipiente, mas com interessantes abordagens, relacionando séries televisivas popularizadas por serviços de streaming entre jovens e adultos (LACERDA, 2018; HENRY, 2018).

Tais espaços de arte audiovisual possuem força pedagógica, aliando imagens e sons e, assim, causando impressões emocionais nos espectadores. A ampliação de experimentações e 
vivências por meio das personagens, propicia reflexões acerca de questões jurídicas, observando como elas são tratadas e, mesmo, propondo maneiras inovadoras de solucioná-las (VILLEZ, 2014). São, por isso, importantes ferramentas para a educação e pesquisa em direito:

\begin{abstract}
A incorporação crítica dos fenômenos da cultura visual, seja mediante a utilização e inclusão de tecnologias visuais para registrar dados, a participação de aspectos visuais de situações educacionais e culturais em estudos ou o uso de imagens gráficas (fotoensaio, historietas e filmes) no processo de comunicar os resultados de uma pesquisa, requer atenção ao contexto social. Como práticas sociais, os rituais escolares, rotinas e todo tipo de interações pedagógicas não podem operar independentemente de seus contextos sociais, sempre levando em conta situações do passado e ajudando a imaginar acontecimentos futuros (FISCHMAN; SALES, 2014, p. 426).
\end{abstract}

Para as finalidades deste texto, aponta-se a necessidade de observar as propostas fílmicas das obras aqui trazidas, a fim de compreender o alcance de suas imagens. Ali, há uma variabilidade de entendimentos, inúmeras possibilidades de encaixe de produção de sentidos, e não, meramente, transmissão de ideias e conceitos. Ao final, cultura popular e cultura acadêmica podem, juntas, possibilitar maior democratização dos conhecimentos jurídicos. É do que passa-se a tratar.

\title{
4 Protocolo de atuação das práticas pedagógicas e conexões possíveis entre biopoder,
} biopolítica, artefatos audiovisuais e direito

Conceitos de biopoder e biopolítica são valiosos para pensar o direito na contemporaneidade e, entende-se, tornam-se mais compreensíveis por meio da experimentação audiovisual. De maneira que as atividades foram pensadas para aproximar os conceitos potencialmente desconhecidos ao conhecimento anterior dos participantes, como forma de potencialização do aprendizado. Utilizou-se, para isso, da técnica de construção sobre conhecimento existente, bem como da utilização de histórias familiares e mídias como 
filmes e séries televisivas para auxiliar na manutenção do interesse e da motivação para aprender (National Research Council, 2000).

Assim, o objetivo das práticas é o de estimular os participantes a pensar sobre como as materialidades do biopoder e da biopolítica permeiam a vida social, de modo a tornar os conceitos mais concretos e assim melhorar sua aprendizagem. Elegeu-se para as propostas aqui apresentadas três obras: o filme What Happened to Monday (NETFLIX, 2017), episódios da série Futurama (20TH CENTURY FOX TELEVISION, 2000) e da série Steven Universe (CARTOON NETWORK STUDIOS, 2017). A partir delas, procurou-se observar como atuam os referidos conceitos em relação ao direito de reprodução, ao direito à própria morte e ao direito de autodeterminação.

Organizam-se as três práticas pedagógicas em quatro etapas, sendo que as três primeiras ( $\mathrm{a}, \mathrm{b}$ e c) possuem desenvolvimento similar para todas as obras audiovisuais. A diferenciação entre elas ocorre no que concerne à última etapa (d), pois, dependendo da série ou filme, dependerá a faixa etária e o debate sobre o direito em questão. É de se notar que a própria linguagem a ser utilizada irá variar de acordo com o público escolhido.

Propõem-se, inicialmente, (a) a apresentação dos conceitos, explorando os exemplos indicados por Michel Foucault (2008; 2010), imbricados com aspectos da vida, morte, saúde, enfim, do controle de populações. Segue-se (b) o debate, onde se estimula os participantes a buscar exemplos de biopoder e biopolítica em mídias que lhes sejam familiares, como filmes, séries televisivas, livros, músicas, entre outros.

Faz parte das práticas pedagógicas, ainda, (c) a escolha por cada dupla de alunos de uma obra que materialize ao menos um desses conceitos, para, posteriormente, ser apresentada para o resto da turma: (c1) primeiro um breve resumo da obra escolhida, depois (c2) de que forma a história apresenta o conceito trabalhado. A partir daí, as três propostas se diferenciam no que diz respeito às obras utilizadas, pois para cada uma delas, (d) um direito é problematizado tendo por ponto de partida o debate sobre o filme ou série televisiva

Ao todo, três obras foram escolhidas para serem utilizadas como exemplo em grupos de diferentes faixas etárias, de modo a apresentar um conteúdo apropriado, mas que também retivesse o interesse dos participantes. Além disso, elas possuem tempo de duração variado, 
de modo que podem ser apresentadas para os participantes de acordo com o tempo programado para a atividade, ainda que sua apresentação não seja necessária para completar a atividade.

O filme de ficção científica What Happened to Monday (NETFLIX, 2017) foi escolhido para o público maior de 16 anos, e possui duração de 123 minutos. A obra apresenta uma sociedade futurista na qual o crescimento populacional levou à escassez de alimentos, de modo que a população foi contida por meio de uma rígida política de filhos únicos, apresentada para a sociedade através da simples declaração "irmãos concebidos ilegalmente serão enviados para hibernação pela Agência” (NETFLIX, 2017). Assim, irmãos nascidos em contrariedade à restrição seriam removidos pela polícia, ostensivamente para serem colocados em sono criogênico, mas na realidade para serem executados e incinerados. Neste contexto, sete irmãs protagonizam o filme, sua própria existência se apresentando como resistência ao poder estatal, e ameaçando todo o sistema de controle populacional caso fosse divulgada.

A obra foi escolhida por apresentar uma biopolítica facilmente visualizável: a limitação da reprodução. Além disso, ela permite apresentar relações de poder como as descritas por Foucault $(2001 ; 2014)$, na forma de como o poder não é simplesmente retido pelo Estado e exercido sobre a população, mas sim de que circula entre as relações sociais. A determinação do Estado em não permitir o nascimento de mais de um filho é foco de diversas resistências no decorrer do filme.

Inicialmente, a mãe das protagonistas exerce resistência ao dar à luz em segredo; posteriormente, o avô resiste ao acobertar as irmãs durante a infância; e finalmente, pelas protagonistas, ao viverem como um único indivíduo. Quando descobertas, igualmente na forma como reagiram, utilizando-se de negociação, sobrevivência, fuga, luta corporal e sacrifício, ao invés de se entregarem. O poder também existe nas sete irmãs e suas ações resultam na extinção da vedação de irmãos, ainda que essa resistência não ocorra sem custos, porque ao final somente duas das sete irmãs conseguem sobreviver.

Já o episódio A Clone of My Own (20 ${ }^{\mathrm{TH}}$ CENTURY FOX TELEVISION), décimo episódio da segunda temporada da série Futurama, elegido para o público maior de 12 anos e duração de 22 minutos, apresenta uma sociedade no século XXX. Nela, os idosos são 
capturados após atingirem a idade de 160 anos e levados para uma estação espacial, onde são mantidos vivos por meio de aparelhos, em um estado de coma induzido.

O episódio foi selecionado por apresentar outro aspecto do biopoder. Nesse contexto, ele estabelece a negativa do direito de morte. Assim, a biopolítica de impedir a morte natural e obrigar a população a viver em um estado permanente de coma é aplicada mesmo que contra a vontade dos envolvidos. Ainda, a resistência está presente nesse episódio na medida em que os amigos e familiares de Farnsworth, que foi capturado ao atingir a idade limite, o resgatam com sucesso da estação para que possa viver o resto de sua vida natural sem o auxílio de aparelhos.

Finalmente, o episódio The Zoo (CARTOON NETWORK STUDIOS, 2017), décimo quarto episódio da quarta temporada da série Steven Universe, de classificação livre e com duração de 11 minutos, apresenta um zoológico humano contido em uma estação espacial e gerido por uma espécie de vida alienígena inorgânica. Ali, as pessoas têm cada aspecto da sua vida gerido por instruções em áudio, que informam os horários das refeições, de lazer e de descanso, e também escolhem os momentos de reprodução, bem como quem serão os indivíduos selecionados para se reproduzirem.

A maioria das pessoas no zoológico é produto de gerações naquele espaço, seus antepassados tendo sido colhidos na Terra há milhares de anos em preparação para a destruição do planeta. Quando dois novos integrantes são trazidos, inicialmente seguem as instruções, até o momento em que um deles é selecionado para reprodução. A partir daí, ambos resistem ao processo, fazendo com que os outros membros do zoológico passem também a resistir, levando a uma rebelião.

O biopoder está presente nas escolhas sobre a vida biológica que são realizadas pela gestão do zoológico, estabelecendo regras para alimentação, sono, lazer e reprodução, visando controlar todos os aspectos da vida biológica, ainda que ao final não tenham sucesso em manter a população sob controle.

Entende-se que as quatro etapas acima referidas permitem trazer ao debate tanto elementos artísticos presentes nas obras audiovisuais quanto suas conexões possíveis com os conceitos de biopoder e de biopolítica, assim como os aspectos jurídicos daí decorrentes. A 
estratégia pedagógica de aliar a cultura acadêmica com a cultura popular é ela própria, ressalta-se, uma possibilidade de resistência ao dogmatismo, unidisciplinariedade e descontextualização do ensino jurídico moderno.

\section{Considerações finais}

O biopoder, conceito desenvolvido por Michel Foucault, é caracterizado de modo genérico como controle da população e da vida biológica. Ele pode ser visualizado em diversas obras de ficção, que muitas vezes levam a extremos uma série de técnicas biopolíticas empregadas em sociedades contemporâneas. A regulação jurídica, parte atuante nessas relações de poder, pode, da mesma forma, ser ali identificada.

O protocolo de atuação das práticas pedagógicas aqui trazido, ao possibilitar a construção conjunta do conhecimento, potencializa a motivação ao aprendizado e aprofunda a experimentação conceitual. Ao buscar pelas características desses conceitos, estimula os participantes a buscar situações em que estejam presentes tanto estratégias biopolíticas quanto normas jurídicas em obras da cultura popular de seu interesse.

Além disso, ao relacionar-se o arcabouço teórico com a cultura popular, é possível estimular nos participantes a reflexão a respeito das diversas materializações do biopoder, da biopolítica e do direito que lhes é correlato, seja na obra de ficção, seja em suas próprias vidas, bem como despertar o interesse pelos estudos foucaultianos.

\section{Referências}

A Clone of My Own. Futurama. Diretor: Rich Moore. Estados Unidos: 20th Century Fox, 2000.

AITH, Fernando. Morte Digna: Direito Natural do Ser Humano. Revista de Direito Sanitário. São Paulo, v. 08, n. 01, p. 173-187, mar./jun. 2007.

AÑEZ, Camila. Bioética e direitos humanos: o direito à morte fundamento na dignidade. Filogenese. São Paulo, p. 15-24, v. 07, n. 01, 2014. 
AQUINO, Mauricio de. Uma análise dos artigos sobre Direito e Cinema no "GT - Direito, Arte e Literatura" no Conpedi (2005-2015). Revista de Direito, Arte e Literatura, Curitiba, v. 02, n. 02, p. 70-91, jul.-dez., 2016.

ASIMOW, Michael (ed.). Lawyers in your living room. Chicago: ABA Publishing, 2009.

BEANE, James. Integração Curricular: A Essência de uma Escola Democrática. Currículo sem Fronteiras, v. 03, n. 02, jul-dez, p. 91-110. 2003. Disponível em: <www.curriculosemfronteiras.org>. Acessado em: 08 de agosto de 2019.

BRAGA, Sandra Rodrigues; Vlach, Vânia Rúbia Farias. Os usos políticos da tecnologia, o biopoder e a sociedade de controle: considerações preliminares. Revista Electrónica de Geografia y Ciencias Sociales, Barcelona, v. VIII, n. 170 (42), ago., 2004. Online. Disponível em: <http://www.ub.edu/geocrit/sn/sn-170-42.htm>. Acessado em: 08 de outubro de 2018.

CARELLI, Rodrigo de Lacerda. Black Mirror: direito e sociedade. Rio de Janeiro: Lumen Juris, 2018.

CRAWLEY, Karen. Beyond the War on Graffiti: the right to visual expression in urbans spaces. Griffith Journal of Law \& human dignity, Art Issue, p. 85-107, 2015.

DHALIWAL, Manpreet (Preeti) Kaur. Re-embodying Jurisprudence: using theatre and multimedia arts-based methods to support critical thinking, feeling and transformation in law. Thesis submitted in partial fulfillment of the requirements for the degree of Master of Laws in the Faculty of Law, University of Victoria. 2017.

DIAS, Renato Duro. Interdição de Gênero: a lei que silencia o corpo. In: TRINDADE, André Karam; GALUPPO, Marcelo Campos; SOARES, Astreia (orgs.). Direito, Arte e Literatura. Florianópolis: CONPEDI, 2015. p. 467-484.

DUONG, Wendy Nicole. Law is Law, Art is Art and shall the two ever meet? - Law and Literature: the comparative creative processes. Southern California Interdisciplinary Law Journal, v. 15:1, p. 01-42, 2005.

FAGUNDES, Mari Cristina de Freitas; HENNING, Ana Clara Correa. "Cara pra Bater, mas sem Covardia, o Tapa Vai Doer, Barriga Vazia": problematizando o sistema de justiça criminal e suas verdades a partir da pesquisa empírica com compositores de rap. Revista Cognitio Juris, ano VII, n. 17, p. 144-172, jun., 2017.

FAGUNDES, Mari Cristina de Freitas; HENNING, Ana Clara Correa. Imagens-intermitentes e Imagens-diagrama em Representações da Justiça: táticas e estratégias da governamentalidade no ensino jurídico brasileiro. In: LEITE, Maria Cecília Lorea; HENNING, Ana Clara Correa; DIAS, Renato Duro (org). Justiça Curricular e suas Imagens. Porto Alegre: Sulina, 2018. p. 219-260. 
FISCHMAN, Gustavo E.; SALES, Sandra. Iconoclash: reflexões sobre cultura visual e pesquisa em Educação. Educação, Porto Alegre, , v. 37, n. 03, p. 423-432, set.-dez. 2014.

FOUCAULT, Michel. Vigiar e punir. Tradução de Raquel Ramalhete. Petrópolis: Vozes, 2001.

FOUCAULT, Michel. Segurança, território e população. Tradução de Eduardo Brandão. São Paulo: Martins Fontes, 2008. Aulas: 11, 18 e 25 de janeiro de 1978.

FOUCAULT, Michel. Em defesa da sociedade. Tradução de Maria Ermantina Galvão. 2 ed. São Paulo: Martins Fontes, 2010.

FOUCAULT, Michel. História da sexualidade I: a vontade de saber. Tradução de Maria Thereza da Costa Albuquerque e J. A. Guilhon Albuquerque. Rio de Janeiro: Paz e Terra, 2014. Capítulo 5.

FRANCA FILHO, Marcílio; LEITE, Geilson Salomão; PAMPLONA FILHO, Rodolfo (orgs). Antimanual de Direito \& Arte. São Paulo: Saraiva, 2016.

GONZÁLEZ, José M. González García. La Mirada de la Justicia: ceguera, venda en los ojos, velo de ignorancia, visión y clarividencia en la estética del derecho. La Balsa de la Medusa: Madrid, 2016.

GRÜNE, Carmela (org). Samba no Pé \& Direito na Cabeça. São Paulo: Saraiva, 2012.

HENNING, Ana Clara Correa. Conexões entre cultura popular e cultura acadêmica: recontextualização curricular na prática de pesquisa jurídica do curso de Direito da Anhanguera Educacional/Faculdade Atlântico Sul em Pelotas. Dissertação apresentada ao Mestrado em Educação da Universidade Federal de Pelotas. Pelotas, 2008.

HENNING, Ana Clara Correa. Relações Jurídicas de Uso e Apropriação Territorial em Comunidades Quilombolas Brasileiras: embates de poder e decolonialismo jurídico sob lentes etnográficas e etnodocumentárias. Tese apresentada no Programa de Pós-graduação HENRY, Amy. Criminal Heroes in Television: Exploring Moral Ambiguity in Law and Justice. Thesis submitted to the Department of Criminology in partial fulfillment of the requirements for Master of Arts in Criminology. Wilfrid Laurier University, Waterloo, 2018.

Stricto Sensu - Doutorado em Direito, da Universidade Federal de Santa Catarina. Florianópolis, 2016.

KIPPER, Aline. O Discurso Jurídico na Sala de Aula: Convencimento de um Único Paradigma. In: RODRIGUES, Horácio Wanderlei (org.). Ensino Jurídico: para que(m)? Florianópolis: Fundação Boiteux, 2000. p. 64-73.

LEITE, Maria Cecília Lorea. Imagens da Justiça, currículo e pedagogia jurídica. In: LEITE, Maria Cecília Lorea (Org.). Imagens da Justiça, currículo e educação jurídica. Porto Alegre: Sulina, 2014. p. 15-57. 
LEITE, Maria Cecília Lorea; VAN-DÚNEM, José Octavio Serra; HENNING, Ana Clara Correa (orgs). Contemporaneidade, Imagens da Justiça e Ensino Jurídico. São Leopoldo: Casa Leiria, 2016.

MARTINEZ, Renato de Oliveira. Direito e Cinema no Brasil: perspectivas para um campo de estudo. Dissertação apresentada no Programa de Pós-Graduação em Direito da Universidade Federal de Santa Catarina. Florianópolis, 2015.

National Research Council. How People Learn: Brain, Mind, Experience, and School: Expanded Edition. Washington, DC: The National Academies Press, 2000. Online. Disponível em: <https://doi.org/10.17226/9853>. Acessado em: 8 out. 2018.

OLIVEIRA, Eliene Rodrigues de; SOUSA, Jaqueline Fernandes. Teatro no Direito - um relato de memórias. II Encontro Internacional de Direito Culturais, Fortaleza, UNIFOR, 09 a 12 de outubro, 2013.

OLIVO, Luis Carlos Cancellier de (org). Novas Contribuições à Pesquisa em Direito e Literatura. Florianópolis: UFSC, 2012.

ROBSON, Peter. Women Lawyers on TV - the British Experience. NAVEIÑ REET: Nordic Journal of Law and Social Research, n. 5, p 101-116, 2014.

SOUSA, Ana Maria Viola de; NASCIMENTO, Grasiele Augusta Ferreira. Direito e Cinema uma visão interdisciplinar. Revista Ética e Filosofia Política, n. 14, v. 2, p. 103-124, out., 2011.

STRECK, Lenio Luiz; TRINDADE, André Karan (org.). Direito e Literatura: da realidade da ficção à ficção da realidade. São Paulo: Atlas, 2012.

The Zoo. Steven Universe. Diretores: Joe Johnston; Ricky Cometa; Elle Michalka. Estados Unidos: Cartoon Network Studios, 2017.

VALERIO, Nitrato Izzo. Interprétation, musique, droit: performance musicale et exécution de normes juridiques. Revue Interdisciplinaire d'Études Juridiques, v. 58, p. 99-127, 2007/1.

VILLEZ, Barbara. Imagens da Justiça: o uso pedagógico das séries policiais de TV. In: LEITE, Maria Cecília Lorea (org.). Imagens da Justiça, Currículo e Educação Jurídica. Porto Alegre: Sulina, 2014.

What Happened to Monday. Diretor: Tommy Wirkola. Produtora: Raffaella De Laurentiis. Reino Unido, França, Bélgica: Netflix, 2017. Disponível em: <https://www.netflix.com/title/80146805>. Acessado em: 20 set. 2018.

WOLKMER, Antonio Carlos; HENNING, Ana Clara Correa. Aportes Saidianos para um Direito (Des)Colonial: sobre iconologias de revoluções e odaliscas. Revista Sequencia, Florianópolis, n. 77, p. 51-88, nov., 2017. 